\title{
Vesico-ureteric reflux in adults with neuropathic bladders treated with Polydimethylsiloxane (Macroplastique ${ }^{\mathrm{R}}$ )
}

\author{
N Shah*,1, MJ Kabir ${ }^{2}$, T Lane ${ }^{2}$, S Avenell ${ }^{1}$ and PJR Shah ${ }^{1,2}$ \\ ${ }^{1}$ Spinal Injuries Unit, Royal National Orthopaedic Hospital, Stanmore, Middlesex, UK; ${ }^{2}$ Institute of Urology \& \\ Nephrology, London, $U K$
}

\begin{abstract}
Objective: To establish the efficacy of Macroplastique ${ }^{\circledR}$ in treating vesico-ureteric reflux (VUR) in adults with neuropathic bladder dysfunction.

Patients and methods: Fifteen patients (12 male and three female), age range 19 to 80 years (mean age 38) were included in this study. Diagnosis was confirmed by videourodynamics. In seven patients reflux was present bilaterally. Twenty-two refluxing ureters were treated. Twelve patients had detrusor hyper-reflexia, two had areflexic bladders and one had loss of bladder wall compliance. According to the International Grading System, 10 ureters had grade IV reflux, five had grade III reflux, five had grade II reflux, and two had grade I reflux. Macroplastique $^{\circledR}(0.5-1.5 \mathrm{ml})$ was injected submucosally under each ureteric orifice to convert the opening to a slit like shape. The patients were followed up from 9 to 68 months. Results: VUR was completely resolved in 72.7\% (16) ureters following a single injection and in a further $4.5 \%$ (1) ureter following a second injection. 9.1\% (2) ureters were improved and treatment failed in $13.7 \%$ (3) ureters. Two patients showed a recurrence of reflux 1 and 4 years after primary injection and subsequently had a curative second injection. Most of the patients in whom VUR was cured or improved showed a reduction in laboratory proven urinary infection rates.

Conclusion: Macroplastique ${ }^{\circledR}$ produced an excellent result $(86 \%$ with complete resolution or improvement of reflux) in treating VUR in adult neuropathic bladders. This is comparable to larger studies carried out on the paediatric population. This is an easy procedure, which avoids major surgery and can be performed as a day case. In cases of failure or recurrence, repeat injection or open surgery can be undertaken without any added complications.
\end{abstract}

Spinal Cord (2001) 39, $92-96$

Keywords: vesico-uretic reflux; endoscopic injection; Macroplastique ${ }^{\circledR}$; neuropathic bladder

\section{Introduction}

Vesico-ureteric reflux (VUR) is a major cause of morbidity in patients with neuropathic bladder dysfunction. ${ }^{1}$ If left untreated it may result in hydronephrosis and ascending urinary tract infection (UTI), resulting in progressive renal deterioration, ${ }^{2}$ which may finally lead to renal failure.

Whilst open surgical anti-reflux procedures are effective in correcting reflux, they are not free from complications even in the best hands. Furthermore, these procedures are more difficult in thick walled trabeculated neuropathic bladders often with less rewarding results as compared to correction of primary VUR. ${ }^{3,4}$

Correction of VUR by endoscopic injection of Teflon paste was first described by Matovschek in

*Correspondence: N Shah, Spinal Injuries Unit, Royal National Orthopaedic Hospital, Brockley Hill, Stanmore, Middlesex HA7 4LP, UK
$1981 .^{5}$ Since then, numerous investigators have reported encouraging results of endoscopic correction of both primary and secondary VUR mostly in children. ${ }^{6-12}$ Little experience is reported in adults with neuropathic bladder dysfunction. Foley et $a l^{13}$ previously reported our unit's treatment of a small series of secondary VUR in adults with neuropathic bladders. Here we report on a large series of patients with neuropathic bladder dysfunction undergoing endoscopic injection of Macroplastique ${ }^{\circledR}$ (Uroplasty BV, Maastricht, The Netherlands) to treat VUR.

Macroplastique ${ }^{\circledR}$ implants are sterile, nonpyogenic, solid textured polydimethylsiloxane particles suspended in a hydrogel carrier. Upon implantation, the hydrogel is substituted by body fluids. Host fibroblasts subsequently deposit collagen around the Macroplastique $^{\mathrm{R}}$ particles, which hold them in place. The hydrogel is later removed by the reticuloendothelial 
system and excreted unmetabolised through the kidneys.

\section{Patients and methods}

Twenty-two refluxing ureters in 15 patients (12 male and three female), aged between 19 and 80 years (median age 38 years) were treated by Macroplastique $^{\mathrm{R}}$ injection between 1993 and 1998 (Table 1). Neuropathic bladder dysfunction was secondary to spinal cord injury in 13 patients, spina bifida in one patient and following surgical removal of a sacral sarcoma in one patient (patient 13). Twelve patients had detrusor hyper-reflexia (DH), two had areflexic bladders and one had loss of bladder wall compliance (LOC). All patients with $\mathrm{DH}$ were on oxybutynin except those on condom drainage relying on $\mathrm{DH}$ for bladder emptying (patients 7,9,11) and patient 5 who had a SARSI (Sacral Anterior Root Stimulator Implant). The latter four patients did not wish to take oxybutynin and thus alter their preferred bladder management. Despite a maximum daily dose of oxybutynin, patient 14 had persistent high pressure $\mathrm{DH}$. The rest of the patients on oxybutynin had well suppressed detrusor pressures. Preoperative assessment included documentation of current bladder management and frequency of UTI.

VUR was confirmed and graded as per the International Grading System ${ }^{14}$ by videourodynamics (VCMG) in every patient. In seven patients reflux was present bilaterally. According to the International Grading System, 10 ureters had grade IV reflux, five had grade III reflux, five had grade II reflux, and two had grade I reflux. Patients 7, 9 and 11 on condom drainage, patient 5 with SARSI and patient 14 with poorly controlled DH on oxybutynin had high pressure $\left(>30 \mathrm{cmH}_{2} \mathrm{O}\right)$ VUR. The remainder of the patients had low pressure $\left(<20 \mathrm{cmH}_{2} \mathrm{O}\right)$ VUR.
Patients with symptomatic UTI or bladder stones had these treated prior to Macroplastique ${ }^{\circledR}$ injection. The procedure was usually performed as a Day Case. Patients were treated under general anaesthesia to reduce the difficulty with autonomic dysreflexia and received an intravenous antibiotic (gentamicin $80 \mathrm{mg}$ ) at induction. Using an aseptic technique the lumen of the endoscopic needle, pre-lubricated with E-Z Gel ${ }^{\mathrm{TM}}$ and attached to a Macroplastique ${ }^{\mathbb{R}}$ syringe, was primed. The needle was passed down the instrument channel of a Miller cytoscope. Under direct vision the mucosa was punctured approximately $0.5 \mathrm{~cm}$ below the ureteric orifice and the needle was advanced submucosally approximately $0.5-1.0 \mathrm{~cm}$ until the needle tip was directly underneath the ureteric orifice. Slowly the Macroplastique ${ }^{\mathbb{R}}(0.5-1.5 \mathrm{ml})$ was injected under the ureter until a volcano-like appearance is achieved, resulting in a crescent-shaped ureteric opening (Figure 1). Both ureters were injected at the same time in bilateral cases.

Patients were followed up at 3 months and thereafter at least annually. The frequency of laboratory proven urinary tract infections requiring antibiotic treatment was recorded at each follow-up from infection diaries. VCMG and an upper urinary tract ultrasound scan were routinely performed postoperatively at 3 months and thereafter at least every 2 years. The results were graded as Cured, Improved (downgrading of reflux) and Failed. Repeat injections were given in cases of failure and recurrence. Open surgical intervention was reserved for those who failed to show any improvement.

\section{Results}

No patients developed postoperative UTI or ureteric obstruction as a result of the procedure. The identification of the ureteric orifice was difficult in

Table 1 Pre-operative patient details

\begin{tabular}{|c|c|c|c|c|c|c|c|c|}
\hline Patient & Age & $\begin{array}{c}\text { Malel } \\
\text { female }\end{array}$ & $\begin{array}{l}\text { Level of } \\
\text { injury } \\
(A S I A)\end{array}$ & $\begin{array}{c}\text { Detrusor } \\
\text { activity }\end{array}$ & $\begin{array}{l}\text { Bladder } \\
\text { management }\end{array}$ & $\begin{array}{l}\text { Reflux } \\
\text { Right }\end{array}$ & $\begin{array}{l}\text { Grade) } \\
\text { Left }\end{array}$ & UTI \\
\hline 1 & 33 & $\mathrm{~F}$ & L1 (A) & Areflexic & ISC & IV & IV & Yes \\
\hline 2 & 80 & $\mathrm{~F}$ & $\mathrm{~T} 10(\mathrm{~B})$ & DH & SPC, oxybutynin & II & IV & Yes \\
\hline 3 & 47 & M & L5 (B) & LOC & SPC, oxybutynin & III & III & No \\
\hline 4 & 35 & M & $\mathrm{T} 1$ (A) & DH & SPC, oxybutynin & I & I & Yes \\
\hline 5 & 41 & M & $\mathrm{T} 10$ (A) & DH & SARSI & III & & Yes \\
\hline 6 & 19 & M & L5 (A) & DH & ISC, oxybutynin & IV & II & Yes \\
\hline 7 & 60 & M & C6 (A) & DH & Condom & IV & II & Yes \\
\hline 8 & 27 & M & T12 (A) & DH & IDUC, oxybutynin & & IV & No \\
\hline 9 & 52 & M & T5 (A) & DH & Condom & & IV & No \\
\hline 10 & 30 & M & C5 (A) & DH & SPC, oxybutynin & & II & No \\
\hline 11 & 43 & $\mathrm{M}$ & $\mathrm{T} 10$ (A) & DH & Condom & III & & Yes \\
\hline 12 & 35 & M & T12 (A) & DH & ISC, oxybutynin & IV & & No \\
\hline 13 & 51 & $\mathrm{~F}$ & S2 (A) & Areflexic & SPC & & III & No \\
\hline 14 & 35 & $\mathrm{M}$ & T6 (A) & DH & ISC, oxybutynin & II & IV & No \\
\hline 15 & 34 & M & C6 (B) & DH & SPC, oxybutynin & IV & & Yes \\
\hline
\end{tabular}

ISC-intermittent self catheterisation 
a

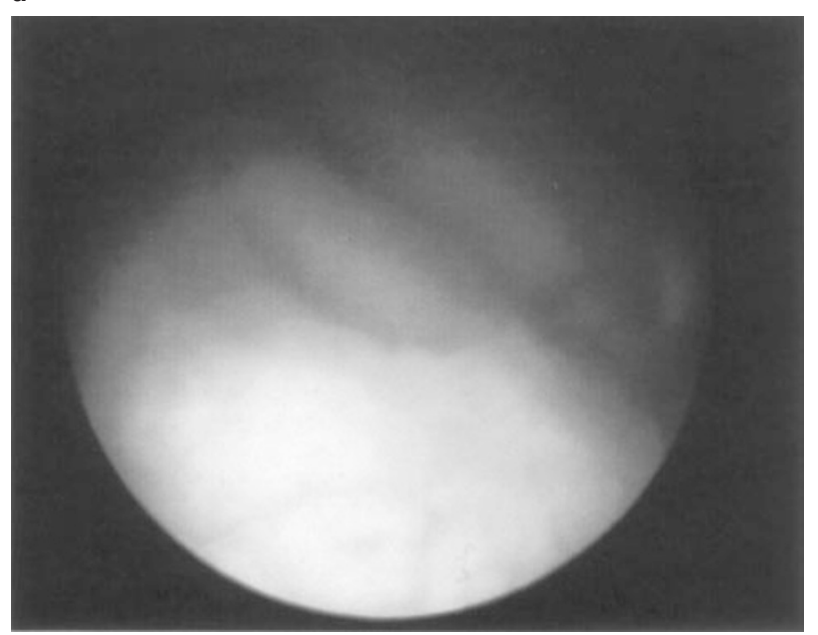

b

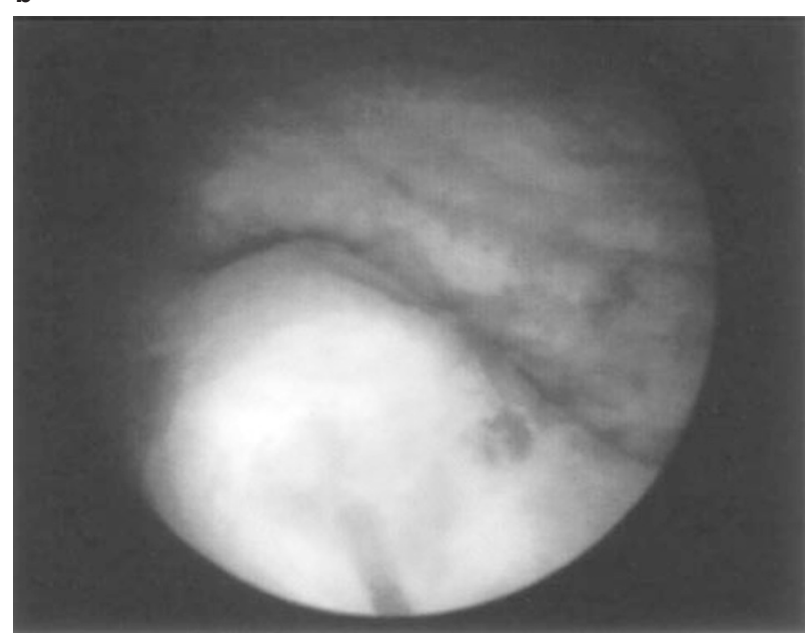

Figure 1 (a) Pre-operative appearance of a right ureteric orifice in a patient. (b) Final result showing a crescent-shaped ureteric opening on top of the augmented tissue patients 2, 10 and 15 who had grossly trabeculated, thick walled bladders. Hence, the procedure was more difficult to perform in these patients.

The mean follow-up was 28.5 months (range from 9 to 68 months). Results for each patient following Macroplastique ${ }^{\circledR}$ injection are shown in Table 2, with overall results shown in Table 3 . Patient 5 developed bilateral VUR (Right grade II, Left grade I) 12 months following the first injection and this was cured following a further injection. Patient 6 developed recurrent bilateral reflux (Right grade IV and Left grade II) 4 years following the first injection and this too resolved following a further injection. Three patients had had pre-operative deterioration in renal function as noted on DTPA isotope studies (patient 2 Right $80 \%$ and Left $20 \%$; patient 6 Right $40 \%$ and Left $60 \%$; patient 7 Right $8 \%$ and Left $92 \%$ ). In each case the deteriorated side corresponded to the higher grade reflux. No improvement in renal function was noted post Macroplastique ${ }^{\circledR}$ injection.

Patients 2 and 15 failed to respond to the first injection of Macroplastique ${ }^{\circledR}$ and are currently awaiting further injection. Both these patients had small capacity (less than $150 \mathrm{ml}$ ), grossly trabeculated, thick walled bladders that were drained by suprapubic catheter (SPC) on free drainage. Furthermore, patient 15 had recurrent problems of bladder stone formation.

Table 3 Overall results of Macroplastique ${ }^{\circledR}$ injection in 22 ureters

\begin{tabular}{lc}
\hline Result & Ureters $(\%)$ \\
\hline Cessation of VUR after first injection & $16(72.7)$ \\
Cessation of VUR after second injection & $1(4.5)$ \\
Downgrading of reflux after one or & $2(9.1)$ \\
$\quad$ two injections & $3(13.7)$ \\
Failure to correct VUR &
\end{tabular}

Table 2 Results following Macroplastique ${ }^{\mathbb{R}}$ injections

\begin{tabular}{|c|c|c|c|c|c|c|c|c|}
\hline \multirow[b]{2}{*}{ Patient } & \multicolumn{2}{|c|}{ Pre-op (grade) } & \multicolumn{2}{|c|}{ Result of 1st injection } & \multirow{2}{*}{$\begin{array}{c}F U \\
(\text { months })\end{array}$} & \multicolumn{2}{|c|}{ Result of 2nd injection } & \multirow{2}{*}{$\begin{array}{c}F U \\
(\text { months })\end{array}$} \\
\hline & Right & Left & Right & Left & & Right & Left & \\
\hline 1 & IV & IV & 0 & III & 36 & & 0 & 12 \\
\hline 2 & II & IV & II & IV & 24 & Awaiting & Awaiting & \\
\hline 3 & III & III & 0 & 0 & 18 & & & \\
\hline 4 & $\mathrm{I}$ & $\mathrm{I}$ & 0 & 0 & 12 & & & \\
\hline 5 & III & & 0 & & 12 & & & \\
\hline 6 & IV & II & 0 & 0 & 48 & & & \\
\hline 7 & IV & II & III & 0 & 42 & & & \\
\hline 8 & & IV & & 0 & 56 & & & \\
\hline 9 & & IV & & 0 & 48 & & & \\
\hline 10 & & II & & 0 & 12 & & & \\
\hline 11 & III & & 0 & & 10 & & & \\
\hline 12 & IV & & 0 & & 21 & & & \\
\hline 13 & & III & & 0 & 9 & & & \\
\hline 14 & II & IV & I & 0 & 68 & & & \\
\hline 15 & IV & & IV & & 12 & & Awaiting & \\
\hline
\end{tabular}


Eight patients (Table 1) had pre-operative recurrent laboratory proven UTI (at least once every 2 months requiring antibiotic treatment). All but two patients (7 and 15) experienced a reduction in the frequency of laboratory proven infections post-operatively. Due to poorly controlled high intravesical pressures in patient 14, a clam-ileocystoplasty was performed with reimplantation of the right ureter in which there was persisting low grade (I) reflux post Macroplastique ${ }^{\mathbb{R}}$ injection. This cured the residual reflux.

\section{Discussion}

Subureteric injection for the correction of VUR was first described in piglets using PTFE (Teflon) in 1984 by Puri and O'Donnell. ${ }^{15}$ Since then there has been 15 years of experience in treating VUR, mainly in children, and in excess of 30 years in the treatment of urinary incontinence using PTFE. ${ }^{8}$ Overall results with PTFE from a European survey have been impressive with $84.9 \%$ of refluxing ureters being cured and a further $10.2 \%$ improving following up to two injections. ${ }^{16}$ Concerns have been raised of the possibility of migration and granulomatous reaction following periurethral Teflon injection ${ }^{17}$ and some anecdotal reports of potential carcinogenesis in humans with Teflon. ${ }^{18,19}$ However, the risk of migration is limited with the small quantity $(<0.3 \mathrm{ml})$ of Teflon used for subureteric injection. For the cases of carcinogenesis reported with Teflon, there has not been a definite causal relationship. ${ }^{8}$

Other injectables used for treating reflux include collagen and Macroplastique ${ }^{\mathbb{R}}$. No randomised controlled trial exists to compare the efficacy of these different injectables. A retrospective review of a 7-year experience by Dodat et $a l^{20}$ reported some superiority of Macroplastique ${ }^{\circledR}$ over Teflon $(93.3 \%$ vs $85.7 \%$ resolution of VUR after one or two injections) and collagen (52.6\% resolution of VUR). Furthermore, the failure rate was least with Macroplastique ${ }^{\circledR}(11.8 \%)$ compared to Teflon $(16.7 \%)$ or collagen $(52.6 \%)$. The failure with collagen being related to resorption, whilst that with Teflon being due to lateralisation and secondary elimination of the product from the injection site due to its fluidity. Macroplastique ${ }^{\circledR}$ was claimed to be superior due to its higher viscosity and absence of retraction.

Concern about safety of silicone has arisen from published reports showing an association between silicone-gel breast implant and connective tissue disorders. ${ }^{21-23}$ But these complications were related to the liquid form of silicone, which had leaked from the implant. ${ }^{24}$ Macroplastique $^{\circledR}$ is an elastomer composed of solid particles and is more inert than silicone gel, causing a mild acute inflammatory reaction that decreases $2-4$ weeks after injection. ${ }^{25}$ There is no convincing evidence that such elastomers are associated with connective tissue disease. ${ }^{26}$

In our experience endoscopic injection of Macroplastique $^{\circledR}$ produced an excellent result $(77 \%$ with complete resolution and a further $9 \%$ with downgrading of reflux) in treating VUR in adult neuropathic bladders. This is comparable to larger studies carried out on the paediatric population. ${ }^{8,20}$ None of our patients developed vesico-ureteric obstruction following the injection. The incidence of the latter is low and usually temporary and is best managed by temporary stenting.

The two failures reported (patient 2 and 15) were both in patients with SPC in small capacity, trabeculated, thick walled bladders further complicated by recurrent bladder stones in patient 15 . Furthermore, Macroplastique ${ }^{\circledR}$ injection was difficult to perform in both these patients due to their bladder wall characteristics. Interestingly, of the 15 patients, six had a SPC in situ for bladder drainage. Two of these six patients had an areflexic bladder on VCMG. The reason for the occurrence of VUR in patients with SPC is not entirely clear, perhaps the catheter tip/ balloon irritates the trigone region thus altering the dynamics of the vesico-urethral junction.

Renal deterioration in spinal cord injured patients with VUR is well documented. ${ }^{2}$ Indeed three of the patients treated had demonstrable renal deterioration affecting the side with higher grade reflux prior to the Macroplastique ${ }^{\mathbb{R}}$ injection. Despite curing the reflux in one of these patients (patient 6), the renal function failed to improve on follow-up isotope renal study. However, we feel that treating VUR should prevent further deterioration in renal function.

Long term follow-up is necessary in this group of patients as delayed recurrence of VUR was noted in two patients (5 and 6). In both these cases repeat injection of Macroplastique ${ }^{\circledR}$ was curative.

Unlike the paediatric population spontaneous resolution of VUR is not expected in adults with secondary reflux. Initial management of VUR secondary to a high pressure neuropathic bladder should be aimed at lowering the intravesical pressures using anticholinergic medication. Intervention is deemed necessary for persisting VUR despite low intravesical pressures and was the case for most of our patients. Patients 7, 9, and 11 wished to continue with condom drainage, hence anticholinergics were considered inappropriate, as was also the case with patient 5 with a sacral root stimulator.

The success rate of open surgical correction of secondary VUR in thickened trabeculated neuropathic bladders is not as good as for reflux in nonneuropathic bladders. ${ }^{3,4}$ Furthermore open surgical procedures further stress already distressed patients with spinal injury. Endoscopic injection of Macroplastique $^{\mathbb{R}}$ is simple, effective and without complications, and can be performed as a day case procedure. Open surgical correction is not complicated by a prior injection of Macroplastique ${ }^{\mathbb{R}}$ and should be reserved for patients who have persisting VUR following failed endoscopic correction.

This study shows that submucosal injection of Macroplastique $^{\circledR}$ to be a simple and effective 
treatment in this difficult group of patients. We would recommend that endoscopic correction should be first line surgical treatment option for the correction of VUR in adult neuropathic bladders.

\section{References}

1 Cosbie Ross J. Vesico-ureteric reflux in the neurogenic bladder. Br J Urol 1965; 52: 164 .

2 Talbot HS, Bunts RC. Late renal changes in paraplegia: Hydronephrosis due to vesico-ureteral reflux. J Urol 1949; 61: 810 .

3 Brereton RJ, Narayanan R, Ratnatunga C. Ureteric reimplantation in the neuropathic bladder. Br J Surg 1987; 74: $1107-1110$

4 Goerdin A, Wyndaele JJ, De-Sy WA. Ureteroneocystostomy in the neuropathic bladder associated with high grade reflux. Eur Urol 1991; 20: 29-32.

5 Matovsscek E. Die Behandlung des vesicorenalon refluxes durch transurethralen einspritzung von teflonpaste. Urologe 1981; 20: $263-266$.

6 Kaplan WE, Dalton DP, Firlit CF. The endoscopic correction of reflux by Polytetrafluoroethylene injection. J Urol 1987; 138: $935-955$.

7 Schulman CC et al. Vesicoureteral reflux in children: Endoscopic treatment. Eur URol 1990; 17: 314-317.

8 Puri P. Ten year experience with subureteric TEFLON (polytetrafluoroethylene) injection (STING) in the treatment of vesico-ureteric reflux. Br J Urol 1995; 75: 126-131.

9 Misra D, Potts SR, Brown S, Boston VE. Endoscopic treatment of vesico-ureteric reflux in neurogenic bladder -8 years' experience. J Paediat Surg 1996; 31: $1262-1264$.

10 Sugiyama $\mathrm{T}$ et al. Endoscopic correction of vesicoureteral reflux in patients with neurogenic bladder dysfunction. Int $J$ Urol Nephrol 1995; 27: $527-531$.

11 Puri P, Kumar R. Endoscopic correction of vesico-ureteral reflux secondary to posterior urethral valves. J Urol 1996; 156: $680-$ 682.

12 Miyakita H, Ninan GK, Puri P. Endoscopic correction of vesicoureteral reflux in duplex systems. Eur Urol 1993; 24: 111-115.
13 Foley SJ, Sheriff MK, Shah PJ. Endoscopic treatment of vesicoureteric reflux in adults with a neuropathic bladder. Spinal Cord 1996; 34: $657-658$.

14 International Reflux Study Committee. Medical versus surgical treatment of primary vesicoureteral reflux. Pediatrics 1981; 67: $392-400$

15 Puri P, O'Donnell B. Correction of experimentally produced vesicoureteric reflux in piglets by intravesical injection of Teflon. $B M J$ 1984; 289: 5 - 7 .

16 Puri P, Ninan GK, Surana R. Subureteric Teflon injection (STING): results of a European survey. Eur Urol 1995; 27: $71-$ 75.

17 Malizia Jr AA et al. Migration and granulomatous reaction after periurethral injection of polytef (teflon). JAMA 1984; 251: 3277 3281.

18 Lewy RB. Experience with vocal cord injection. Ann Oto Rhinol Laryngol 1973; 85: 440-450.

19 Lockhart JL, Walker RD, Vorstman B, Politano VA. Periurethral polytetrafluoroethylene injection following urethral reconstruction in female patients with urinary incontinence. $J$ Urol 1988; 140: 51 .

20 Dodat $\mathrm{H}$ et al. Analysis of the failure of endoscopic treatment of vesico-renal reflux in children using injections of Teflon and collagen and the preliminary results of injections of Macroplastique ${ }^{\mathbb{R}}$. Progrès en Urologie 1995; 5: $58-68$.

21 Spiera H. Scleroderma after silicone augmentation mamoplasty. JAMA 1986; 260: $236-238$.

22 Varga J, Schumacher HR, Jimenez SA. Systemic sclerosis after augmentation mammoplasty with silicone implants. Ann Intern Med 1989; 111: $377-383$

23 Silver RM et al. Demonstration of silicone in sites of connective tissue disease in patients with silicone-gel breast implants. Arch Dermatol 1993; 12: $63-68$.

24 Harriss DR, Jacovou JW, Lemberger RJ. Periurethral silicone microimplants (Macroplastique ${ }^{\mathrm{R}}$ ) for the treatment of genuine stress incontinence. Br J Urol 1996; 78: $722-728$.

25 Beisang AA, Ersek RA. Mammalian response to subdermal implantation of textured microimplants. Aesthetic Plast Surg 1992; 16: $83-90$.

26 Tinkler JB, Campbell HJ, Senior JM, Ludgate SM. Evidence for an association between the implantation of silicones and connective tissue disease. Medical Device Directorate (UK Department of Health) Report, 1993; MDD/92/42: 1-65. 